\title{
Chromosome factors affecting pairing in progenies of $6 x$-triticale $\times$ Triticum turgidum L. ssp. turgidum conv. durum (Desf.)
}

\author{
Angeles Bernardo, \\ Fernando Diaz and \\ Nicolás Jouve
}

\author{
Department of Cellular Biology and Genetics, \\ University of Alcalá de Henares, Apdo. 20, Alcalá de \\ Henares, Madrid, Spain.
}

The chromosome constitution and meiotic behaviour of 15 plants of F2 and BC1 progenies from the hybrid of $6 x$ triticale $\times T$. turgidum (L.) ssp. turgidum conv. durum (Desf.) (F1: $2 \mathrm{n}=5 \mathrm{x}=35$; AABBR) were studied using Cbanding patterns of both wheat and rye chromosomes as identifying features. Patterns in PMCs at first metaphase permitted the individual identification of the chromosomes of nine of the wheat and all of rye in all plants. The external length and internal heterochromatin of chromosomes were analysed and found to influence the meiotic behaviour of each chromosome pair. The existence of effects of both arm length and amount and distribution of heterochromatin on pairing are assumed. The results seem to demonstrate that of the two mentioned factors the first is the most important.

\section{INTRODUCTION}

It has been reported that constitutive heterochromatin present in wheat chromosomes influences meiotic pairing. Interstitial and subtelomeric heterochromatin seems to facilitate the maintenance of chiasmata. Santos and Giraldez (1978), Loidl (1979), Naranjo and Lacadena (1982), Ferrer et al. (1984b), and Dvorak and McGuire (1981) suggested that the differential pairing among genomes of $T$. aestivum could be related to the amount of DNA and heterochromatin present in chromosomes. In general, heterochromatin has been associated with a detrimental effect on chromosome pairing at first metaphase (Yamamoto, 1979; John and Miklos, 1979; Bostock, 1980). It has been speculated that late DNAreplicating heterochromatin interferes in chromosome pairing when rye chromosomes are placed in a wheat genetic background. Modifications in rye chromosomes through the removal of telomeric heterochromatin could improve their level of pairing in triticale (Bennett, 1974, 1980, Darvey and Gustafson, 1975; Gustafson, 1976; Schlegel and Huelgenhof, 1985).

Moreover, pairing and chiasma frequencies have been related to relative arm length in wheat chromosomes. Thus, Sallee and Kimber (1979), concluded that pairing and chiasma formation are correlated with the relative length, in an analysis of chromosome behaviour at first metaphase of meiosis in telocentrics of common wheat "Chinese Spring".

This paper deals with the analysis of the effect of both external (length) and internal (heterochromatin) on homologous chromosome pairing in plants derived from $6 x$-triticale $\times T$. turgidum $\mathrm{L}$. hybrids where the $\mathrm{C}$-banding technique was used to identify individual chromosomes.

\section{MATERIALS AND METHODS}

F1 hybrids $(2 n=5 x=35)$ between $6 x$-triticale and durum wheats (genomes AABBR) were self-pollinated and backcrossed to both triticale and $T$. turgidum (L) ssp. turgidum conv. durum parents to obtain F2 and BC1. From the progenies the following plants were analysed: 11 from the backcross to the durum wheat; 1 from backcross of the hybrid to the $6 x$-triticale; 3 from the selfed F1. The Spanish $6 x$-triticale cultivars "Camarma" (A), "S-14" (B) and "Torote" (C) and the selected durum wheats "Arcipreste" (G), "Victor $\mathrm{Vz} *$ Flamingo 'S", $(\mathrm{H})$, "Alaga * (Bidi $17 *$ Marfed ERT 1)*(Garza 'S'*Candeal)" (P) and "Edmore" (J) served as the parents to obtain the F1. 
In order to quantify both the amount and the arm lengths in somatic chromosomes, karyological analysis was carried out on the triticale variety "Camarma". This cultivar was used because its utilisation as a parent in the majority of plants analysed. Twenty well spread somatic metaphases in which all chromosomes were identifiable by C-banding were examined and studied. Measurements of the lengths of chromosome arms and of their euchromatin and heterochromatin regions were made from enlarged photographs produced using a $\mathrm{BH} 2$ Olympus photomicroscope. To compensate for differences in the degree of condensation of the chromosomes in different cells, the relative lengths with respect to the short arm of chromosome 4B in each cell were used. Rye chromosomes of "Camarma" and segregant plant material were identified according to the internationally agreed karyotype of rye (Sybenga, 1983). The identification of the wheat chromosomes (genomes A and B) was carried out on the basis of their individual pattern of bands previously reported for hexaploid wheat $T$. aestivum L. (Gill and Kimber, 1974a, b; Ferrer et al., 1984a).

The chromosome number and constitution, and the meiotic pairing of each plant were examined in PMCs at first metaphase using the C-banding technique described previously (Jouve et al., 1980). The anthers were fixed in Carnoy's solution and preparations were made following excision of pollen mother cell sacks from the anthers.

\section{RESULTS AND DISCUSSION}

\section{C-banding of somatic chromosomes in $6 x$-Triticale}

The C-banding technique was applied to analyse the amount and distribution of heterochromatin in somatic chromosomes of the $6 x$-triticale variety "Camarma" (A). This is shown in fig. 1. An
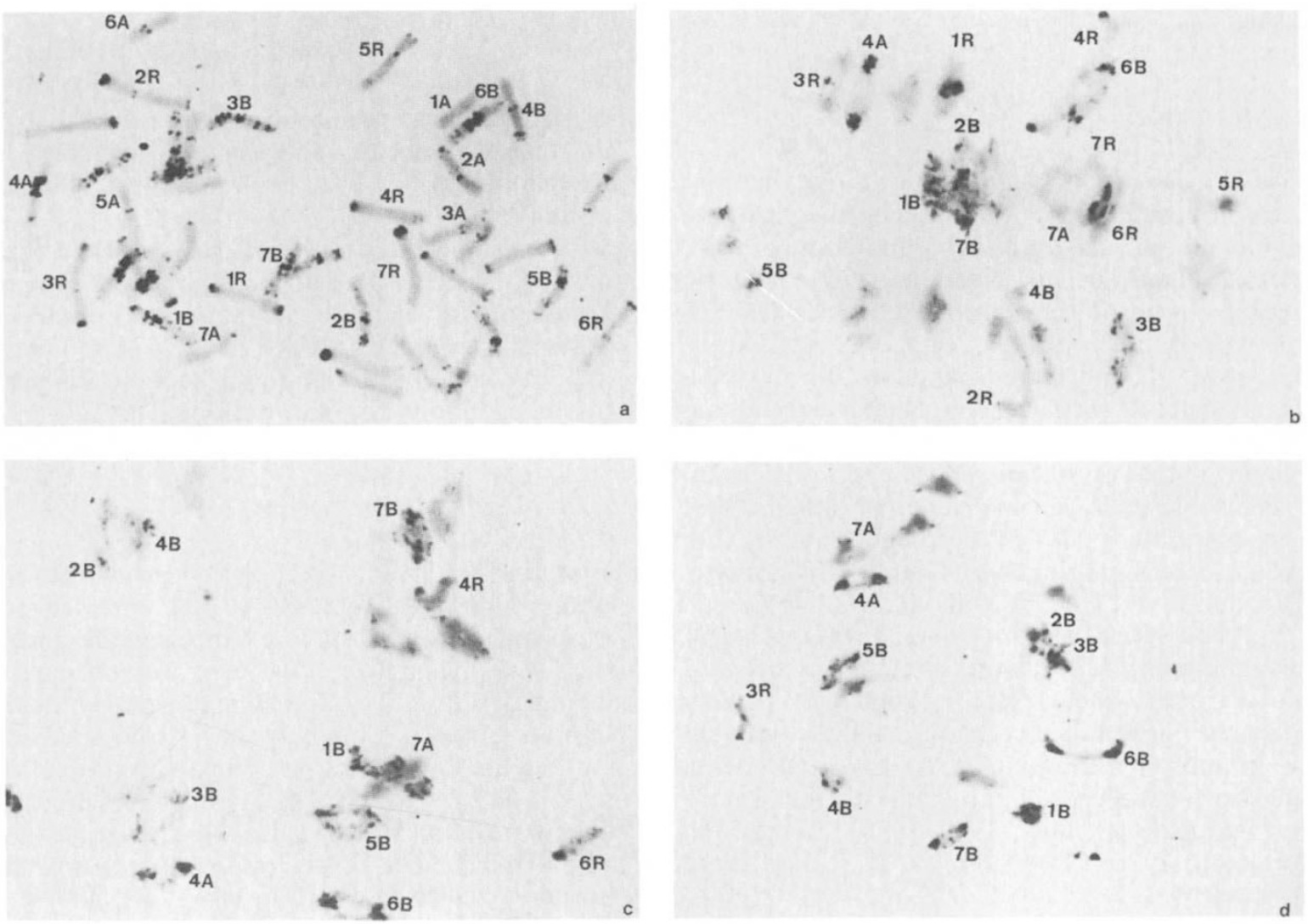

Figure 1 C-banding microphotographs of metaphase plates. (a) somatic metaphase in triticale variety "Camarma". (b) F2 plant: cell showing 14 wheat bivalents +7 rye bivalents. (c) $\mathrm{BC} 1$ plant: cell showing 14 wheat bivalents $+4 \mathrm{R}$ and $6 \mathrm{R}$ univalents. (d) $\mathrm{BC} 1$ plant: cell showing 14 wheat bivalents $+3 \mathrm{R}$ univalent. 
idiogram for each somatic chromosome is presented in fig. 2, together with the "cyclograms" representing the results of meiotic pairing. Identification of chromosomes is based on the standard karyotypes of wheat and rye chromosomes previously reported (Gill and Kimber, 1974a, b). The triticale line "Camarma" contained all seven pairs of rye chromosomes. The results on relative chromosome lengths and heterochromatin amounts are given in table 1.

The amount of heterochromatin present per chromosome varied both within and between genomes. Thus, the mean amount of heterochromatin for each genome was of: $A=14 \cdot 3$ per cent (range $0-36 \cdot 0$ ), $\mathrm{B}=32 \cdot 6$ per cent (range $16 \cdot 2$ $44 \cdot 0$ ), and $R=14 \cdot 1$ per cent (range $9 \cdot 5-18 \cdot 7$ ).

The distribution of heterochromatin was quite different for the wheat and rye chromosomes. Some wheat chromosomes were characterised by the presence of heavy proximal ( 7 of the $B$ genome and $4 \mathrm{~A}$ ) or interstitial (2A, 3A, 5A and 6A) bands. Chromosome $1 \mathrm{~A}$ appeared to lack heterochromatic regions and 7A presented small and terminal bands. Rye chromosomes showed mainly telomeric heterochromatin with the exception of the $5 \mathrm{RL}$ and $6 \mathrm{RL}$ arms.

\section{Chromosome number and constitution in the $F 2$ and $B C 1$ progenies}

All plants analysed possessed 14 wheat chromosomes $\left(7^{\prime \prime} \mathrm{AA}+7^{\prime \prime} \mathrm{BB}\right)$. Two plants had only this chromosome constitution. The chromosome composition of the remaining plants was very variable and there were different monosomic and polysomic additions of rye chromosomes (29 to 40: 7"AA+ $7 " B B+1-12 R / R R)$. Three plants showed a triticale chromosome composition $\left(2 n=42 ; 7^{\prime \prime} \mathrm{AA}+7^{\prime \prime} \mathrm{BB}+\right.$ $\left.7^{\prime \prime} \mathrm{RR}\right)$. These results are shown in table 2 .

\section{Pairing at Metaphase I}

The wheat and rye chromosomes were easily distinguished at meiosis. Nine wheat chromosomes (4A, $7 \mathrm{~A}$ and the seven of the $\mathrm{B}$ genome) and the all rye chromosomes were recognized at first metaphase of meiosis, and the meiotic behaviour was investigated in a sample of PMCs from each F2 and $\mathrm{BC} 1$ plant (fig. $1 b, c$ and $d$ ).

A configuration of 14 bivalents $\left(7^{\prime \prime} \mathrm{AA}+7^{\prime \prime} \mathrm{BB}\right)$ was the most frequent meiotic association observed amongst the wheat chromosomes. The meiotic behaviour of each pair whether univalent, rod bivalent or closed bivalents, differed significantly within the same plant $\left(\chi^{2}=16.48\right.$ to $58.91 ; \mathrm{df}=8$;
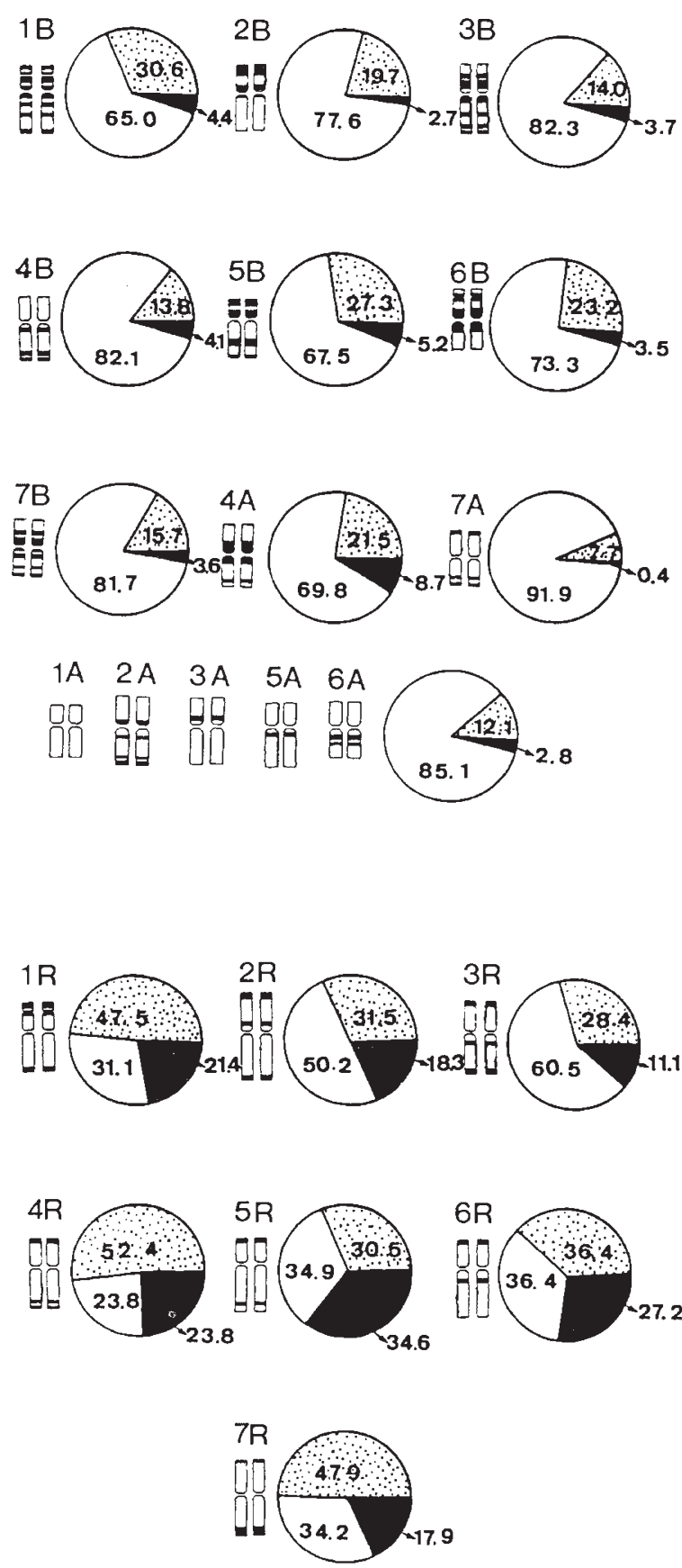

Figure 2 Meiotic behaviour of each chromosome pair. Idiogram for somatic chromosomes near to each cyclogram corresponds to Giemsa C-banding studies for the chromosomes of triticale variety "Camarma". Cyclograms represent the meiotic behaviour showed by the nine identified chromosomes of wheat $(4 \mathrm{~A}, 7 \mathrm{~A}$ and the seven of the $\mathrm{B}$ genomes), the seven rye chromosomes and overall of the remaining of the $\mathrm{A}$ genome. Black sectors=univalents; Dotted sectors = open bivalents; White sectors = ring bivalents. 
Table 1 Arm length (relative to 4BS =1), amount of heterochromatin (\% respect to chromosomic length) of the triticale variety "Camarma" and the mean number of chiasmata in F2 and BC1 plants analysed

\begin{tabular}{|c|c|c|c|c|c|}
\hline & \multirow{2}{*}{$\begin{array}{l}\text { Mean length } \\
\text { (relative to 4BS) }\end{array}$} & \multirow{2}{*}{$\begin{array}{l}\text { Arm } \\
\text { ratio } \\
(\mathrm{L} / \mathrm{S})\end{array}$} & \multicolumn{2}{|c|}{$\begin{array}{c}\text { Amount of } \\
\text { heterochromatin \% }\end{array}$} & \multirow{2}{*}{$\begin{array}{l}\text { Mean } \\
\text { number of } \\
\text { Xata }\end{array}$} \\
\hline & & & Arms & Total & \\
\hline \multicolumn{6}{|c|}{ Wheat* } \\
\hline $1 \mathrm{BS}$ & 0.92 & \multirow{2}{*}{1.98} & $18 \cdot 30$ & \multirow{2}{*}{$41 \cdot 00$} & 0.68 \\
\hline $1 \mathrm{BL}$ & $1 \cdot 81$ & & $22 \cdot 70$ & & 1.09 \\
\hline $2 \mathrm{BS}$ & $1 \cdot 19$ & \multirow{2}{*}{1.32} & 18.47 & \multirow{2}{*}{$21 \cdot 36$} & 0.99 \\
\hline $2 \mathrm{BL}$ & 1.57 & & 2.89 & & 0.91 \\
\hline $3 \mathrm{BS}$ & 1.24 & \multirow{2}{*}{$1 \cdot 35$} & 16.49 & \multirow{2}{*}{$40 \cdot 20$} & 0.87 \\
\hline $3 \mathrm{BL}$ & 1.67 & & $23 \cdot 71$ & & 1.07 \\
\hline 4BS & $1 \cdot 00$ & \multirow{2}{*}{1.59} & 0.00 & \multirow[b]{2}{*}{$16 \cdot 21$} & 0.90 \\
\hline $4 \mathrm{BL}$ & 1.59 & & $16 \cdot 21$ & & 1.03 \\
\hline $5 \mathrm{BS}$ & 0.77 & \multirow{2}{*}{$2 \cdot 01$} & 19.74 & \multirow{2}{*}{$33 \cdot 04$} & 0.70 \\
\hline $5 B L$ & 1.56 & & $13 \cdot 30$ & & 1.27 \\
\hline $6 \mathrm{BS}$ & $1 \cdot 14$ & \multirow{2}{*}{$1 \cdot 03$} & $25 \cdot 86$ & \multirow{2}{*}{$43 \cdot 96$} & 0.77 \\
\hline $6 \mathrm{BL}$ & $1 \cdot 18$ & & $18 \cdot 10$ & & 1.03 \\
\hline 7BS & $1 \cdot 10$ & \multirow{2}{*}{1.09} & $15 \cdot 58$ & \multirow[b]{2}{*}{$32 \cdot 46$} & 0.85 \\
\hline $7 \mathrm{BL}$ & $1 \cdot 21$ & & $16 \cdot 88$ & & 1.06 \\
\hline $4 \mathrm{AS}$ & 1.23 & \multirow{2}{*}{$1 \cdot 10$} & $19 \cdot 37$ & \multirow{2}{*}{36.03} & 0.75 \\
\hline $4 \mathrm{AL}$ & 1.35 & & 16.66 & & 0.96 \\
\hline 7AS & $1 \cdot 11$ & \multirow{2}{*}{$1 \cdot 07$} & $6 \cdot 11$ & \multirow{2}{*}{$13 \cdot 97$} & 1.03 \\
\hline $7 \mathrm{AL}$ & $1 \cdot 18$ & & $7 \cdot 86$ & & 0.99 \\
\hline \multicolumn{6}{|l|}{ Rye ${ }^{\dagger}$} \\
\hline $1 \mathrm{RS}$ & $1 \cdot 14$ & \multirow{2}{*}{1.49} & $11 \cdot 61$ & \multirow[b]{2}{*}{$18 \cdot 65$} & 0.31 \\
\hline $1 \mathrm{RL}$ & $1 \cdot 70$ & & $7 \cdot 04$ & & 0.89 \\
\hline $2 \mathrm{RS}$ & $1 \cdot 71$ & \multirow{2}{*}{$1 \cdot 19$} & 10.72 & \multirow[b]{2}{*}{$15 \cdot 81$} & 0.51 \\
\hline $2 \mathrm{RL}$ & 2.02 & & 5.09 & & 0.87 \\
\hline $3 \mathrm{RS}$ & $1 \cdot 33$ & & 6.73 & & 0.83 \\
\hline $3 R L$ & 1.79 & $1 \cdot 34$ & $11 \cdot 21$ & 17.94 & 0.74 \\
\hline 4RS & $1 \cdot 19$ & & 6.87 & & 0.26 \\
\hline $4 R L$ & 1.72 & 1.44 & 5.49 & $12 \cdot 36$ & 0.79 \\
\hline $5 \mathrm{RS}$ & 1.05 & & 5.88 & & 0.34 \\
\hline $5 \mathrm{RL}$ & $2 \cdot 01$ & 1.91 & 3.59 & $9 \cdot 47$ & 0.72 \\
\hline 6RS & $1 \cdot 16$ & & 5.74 & & 0.37 \\
\hline $6 \mathrm{RL}$ & $2 \cdot 05$ & 1.77 & 4.53 & $10 \cdot 27$ & 0.75 \\
\hline $7 \mathrm{RS}$ & 1.45 & & 2.50 & & 0.61 \\
\hline $7 \mathrm{RL}$ & 1.75 & $1 \cdot 21$ & 11.87 & $14 \cdot 37$ & 0.59 \\
\hline
\end{tabular}

* For chiasmata, data from 15 plants: 1069 PMCs.

$\dagger$ For chiasmata, data from 4 plants with the exception of chromosome 2R (3 plants): 215 PMCs.

$P<0.05$ to $P<0.001)$. However, there were no significant differences between the meiotic configurations scored for the same chromosomes in different plants. Correlation coefficients comparing chiasma frequencies amongst all plants were estimated. The $r$ values of the mean frequencies of metaphase association per chromosome arm were always near 0.9 and in all cases the correlations were significant and positive. Consequently, although differences at the level of pairing amongst plants were found, the variations in the mean number of chiasmata were regularly distributed amongst chromosomes. The variance ratios were not significantly different at the 5 per cent level. This result confirmed the similar tendancies of each wheat chromosome arm to pair independently from both the rye chromosome additions and genetic background. It can be assumed that, although plants differed among themselves in rye chromosome constitution, pairing intensities of wheat arms were uniformly affected under the effect of different rye additions. Evidence in favour of the effect of rye heterochromatin on wheat chromosome pairing are presented in a separate paper (Bernardo et al., 1987). Chromosome pairing in wheat must therefore be controlled by a balance between several factors. Thus, Miller et al. (1983) demonstrated that chromosome pairing is influenced by extra dosage of group 3 chromosomes. The effect of increased dosage of other wheat 
chromosomes on chromosome pairing of individual wheat bivalents was also observed (Miller and Reader, 1985).

As a consequence of similar meiotic behaviour of each chromosome pair in different plants, the individual results can be considered as a whole. Fig. 2 illustrates the frequencies of meiotic configurations for the identified pairs of wheat and rye chromosomes, and summarises data for the remaining chromosomes ( $1 \mathrm{~A}, 2 \mathrm{~A}, 3 \mathrm{~A}, 5 \mathrm{~A}$ and $6 \mathrm{~A})$. The "cyclograms" were obtained by taking data from all the plants analysed, and fig. 3 shows the mean number of chiasmata for the wheat and rye chromosomes. From these results it can be deduced: (a) chromosome 4A and the rye chromosomes carry the largest amount of heterochromatin either around the centromere (4A) or in the telomeres and showed the highest frequency of univalents. (b) wheat chromosomes having the highest arm ratio $(1 \mathrm{BL} / 1 \mathrm{BS}=1.96 ; 5 \mathrm{BL} / 5 \mathrm{BS}=$ $2 \cdot 02$ ) also exhibited a higher frequency of open bivalents (chiasmata in the long arm) than the others having similar lengths in both arms. (c) Contrarily, wheat chromosomes having the lowest arm ratio $(7 \mathrm{AL} / 7 \mathrm{AS}=1 \cdot 06 ; \quad 7 \mathrm{BL} / 7 \mathrm{BS}=1 \cdot 1$; $3 \mathrm{BL} / 3 \mathrm{BS}=1 \cdot 34)$ showed the highest frequencies of ring bivalents. (d) chromosome arms $1 \mathrm{BL}, 3 \mathrm{BL}$, $4 \mathrm{BL}, 2 \mathrm{BS}$ and $7 \mathrm{AL}$, which exhibited subtelomeric or telomeric bands also showed a high level of pairing.

The meiotic behaviour of each chromosome pair in the set of plants analysed may indicate that each chromosome arm seems to pair with a different frequency. Factors upon which pairing intensity seem to depend are heterochromatin and arm size.

Fig. 4 shows the regression lines and correlation coefficients from a comparison of the mean number of chiasmata per chromosome arm with relative amounts of heterochromatin and length. The main observation that can be made is the positive and significant slope for differences in arm length for both wheat and rye chromosomes. The mean number of chiasmata are significantly higher in longer chromosome arms than in short ones. However, there was not a significant correlation between total amount of heterochromatin and mean number of chiasmata either for the wheat or the rye chromosome arms.

These statistical tests confirm previous results on the influence of chromosome size on pairing intensity. For example, Sallee and Kimber (1979) assumed that the different pairing intensity showed by chromosomes of different genomes could be related with their differences in length. Dvorak and
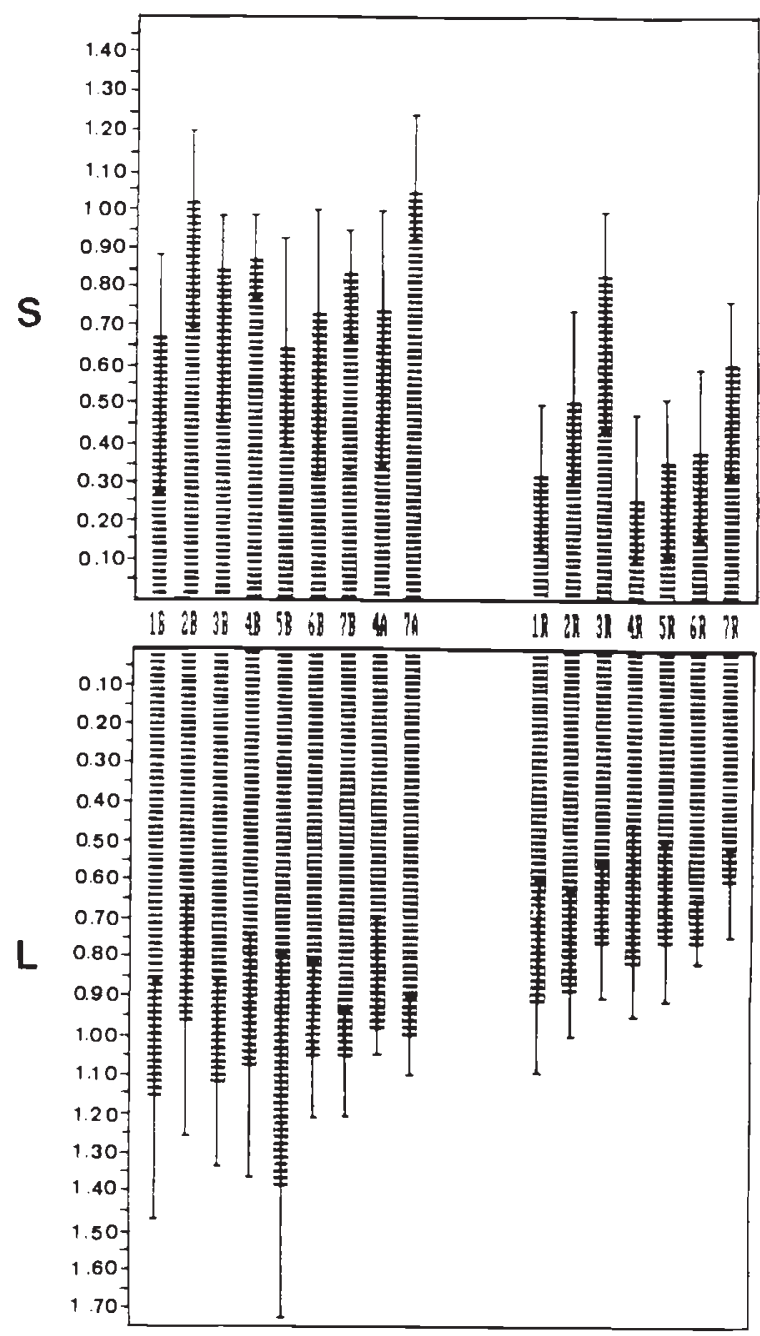

Figure 3 Histograms showing the mean number of chiasmata for each identified wheat and rye chromosome arms $(L=$ long; $\mathrm{S}=$ short)

McGuire (1981) suggested that the variation in pairing frequencies in wheat genomes could be related to the amount of DNA and heterochromatin present in chromosomes. There is a large amount of evidence on the influence of the telomeric heterochromatin of rye chromosomes on meiotic pairing in triticale. Thus, Thomas and Kaltsikes (1974) suggested that the heterochromatin present in the telomeres can affect the processes of DNA replication and prophase pairing observed in the rye chromosomes. This effect becomes critical for rye chromosomes both in triticale and plants with mono- and polysomic additions where a shorter meiotic cycle is forced upon the rye chromosomes (Bennett and Kaltsikes, 1973). 
Table 2 Chromosome constitution of the plants analysed. Plant numbers 1 to 16 are derived from the cross (Triticale $* T$. turgidum) $* T$. turgidum; plant number 17, from (Triticale $* T$. turgidum) * Triticale, and plant numbers 18 to 20 from selfpollinated (Triticale * T. turgidum)

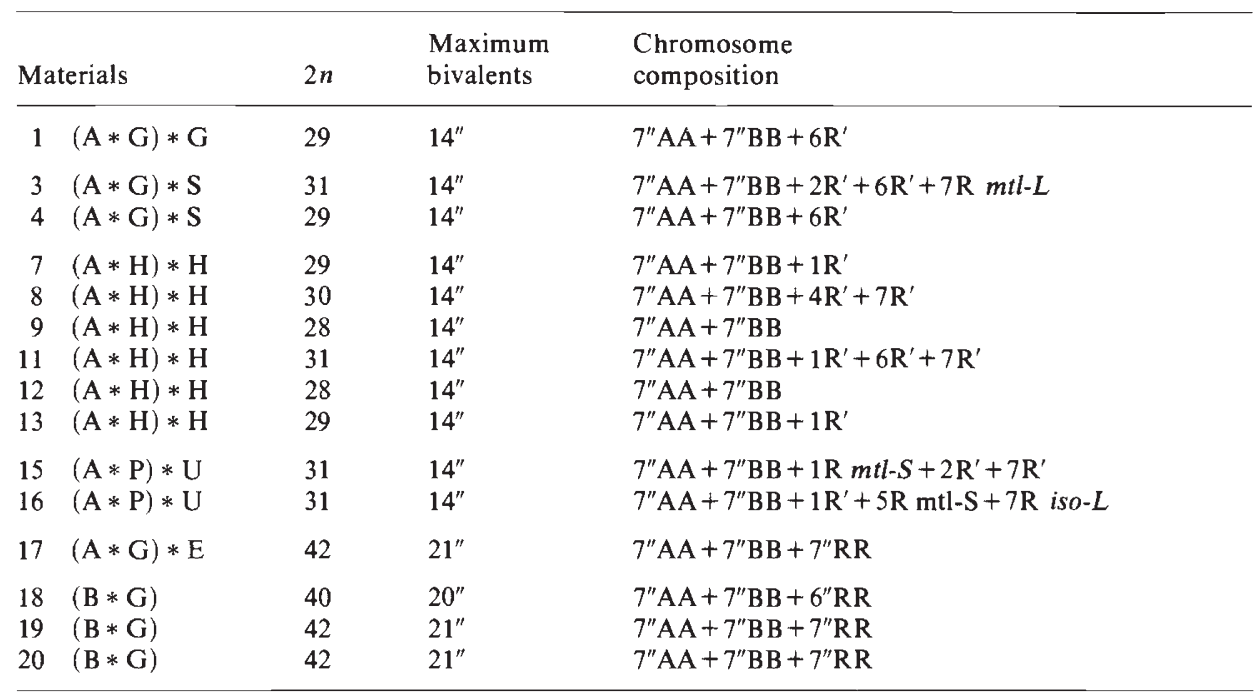
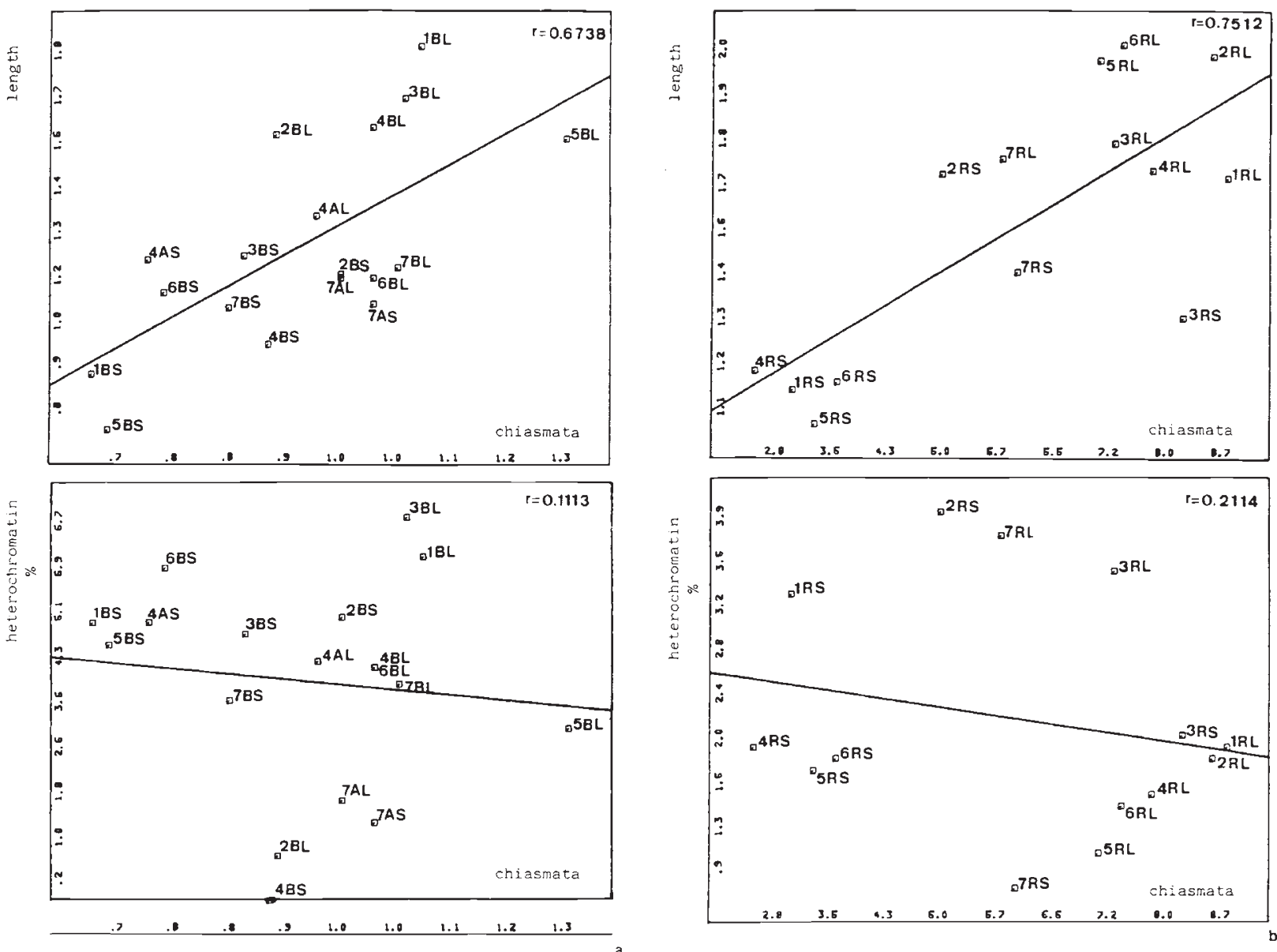

Figure 4 Regression lines comparing the mean number of chiasmata and both relative amount of heterochromatin and length in wheat (A) and rye (B) chromosome arms. The pairing frequencies were also checked against data on chromosome length of Sallee and Kimber (1979) with similar statistical result. 
Interstitial and subtelomeric C-bands of heterochromatin can facilitate the maintenance of chiasmata (Santos and Giraldez, 1978; Loidl, 1979; Naranjo and Lacadena, 1982; Ferrer et al., 1984). This effect could explain the increased pairing observed in the wheat chromosome arms above mentioned. In this case, the increased level of pairing could be explained in terms of heterochromatin interfering with the terminalisation of chiasmata. In any case, meiotic pairing in wheat chromosomes may be influenced by an overlapping effect of both arm length and amount and distribution of heterochromatin. Our results seem to demonstrate that of the two factors the chromosome length is the most important.

Acknowledgements The authors thank the C.A.I.C.Y.T. of Spain for the award of a grant (No. 1558/82) to support this work.

\section{REFERENCES}

BENNETT, M. D. AND KALTSIKES, P. J. 1973. The duration of meiosis in a diploid rye, a tetraploid wheat and a hexaploid triticale derived from them. Can. J. Genet. Cytol., 15, 671-679.

BENNETT, M. D. 1974. Meiotic, gametophitic and early endosperm development in Triticale. In "Triticale" Proc. Int. Symp. El Batán (Mexico) Int. Res. Centre Monogr IDRC024e pp. $137-148$.

BENNETT, M. D. 1980. Theoretical and applied DNA studies and Triticale breeding. Hodowla Roslin Aklim. Nas., 24, 289-298.

BERNARDO, A., GARCIA, M. AND JOUVE, N. 1987. The effect of Secale cereale $\mathrm{L}$. heterochromatin on wheat chromosome pairing. Euphytica, 36: (in press).

BOSTOCK, С. 1980. A function for satellite DNA? T.I.B.S., May, 117-119.

DARVEY, N. L. AND GUSTAFSON, P. J. 1975. Identification of rye chromosomes in wheat-rye addition lines and triticale by heterochromatin bands. Crop Sci., 15, 239-243.

DVORAK, J. AND McGUIRE, P. E. 1981. Nonstructural chromosome differentiation among wheat cultivars, with special reference to differentiation of chromosomes in the related species. Genetics, 97, 391-444.
FERRER, E., GONZALEZ, J. M. AND JOUVE, N. 1984a. Identification of C-banded chromosomes in meiosis of common wheat Triticum aestivum L. Theor. Appl. Genet., 67, 257-261.

FERRER, E., GONZALEZ, J. M. AND JOUVE, N. 1984b. The meiotic pairing of nine wheat chromosomes. Theor. Appl. Genet., 69, 193-198.

GILL, B. S. AND KIMBER, G. 1974a. Giemsa C-banding and the evolution of wheat. Proc. Nat. Acad. Sci., 71, 4086-4090.

GILL, B. S. AND KIMBER, G. 1974b. A Giemsa C-banding technique for cereal chromosomes. Cereal Res. Comm., 2, $87-94$.

GUSTAFSON, P. J. 1976. The evolutionary development of Triticale: the wheat-rye hybrid. Evolutionary Biology, 9, 107-135.

JOHN, B. AND MIKLOS, G. L. C. 1979. Functional aspect of satellite DNA and heterochromatin. Int. Rev. Cytol., 58, $1-114$.

JOUVE, N., DIEZ, M. AND RODRIGUEZ, M. 1980. C-banding in $6 x$-triticale $\times$ Secale cereale L. hybrid cytogenetics. Theor. Appl. Genet., 57, 75-79.

LOIDL, J. 1979. C-band proximity of chiasmata and absence of terminalisation in Allium flavum (Liliaceae). Chromosoma, $73,45-51$.

MILLER, T. E. AND READER, S. M. 1985. The effect of increased dosage of wheat chromosomes on chromosome pairing and an analysis of the chiasma frequencies of individual wheat bivalents. Can. J. Genet. Cytol., 27, 421-425.

MILlER, T. E., READER, S. M. AND GALE, M. D. 1983. The effect of homologous group 3 chromosomes on chromosome pairing and crossability in Triticum aestivum. Can. J. Genet. Cytol. 25, 634-641.

NARANJO, T. AND LACADENA, J. R. 1982. C-banding pattern and meiotic pairing of five rye chromosomes of hexaploid triticale. Theor. Appl. Genet., 61, 233-237.

SANTOS, J. L. AND GIRALDEZ, R. 1978. The effect of C-heterochromatin in chiasma terminalisation in Chrotipus biguttulus L. (Acrididae, Orthoptera). Chromosoma, 70, 59-66.

SALLEE, P. J. AND KIMBER, G. 1979. An analysis of the pairing of wheat telocentric chromosomes. Proc. 5th Int. Wheat Genet. Symp., New Delhi, pp. 408-419.

SCHLEGEL, R. AND HUELGENHOF, E. 1985. Heterochromatin alterations in chromosomes of hexaploid triticale and breeding of Triticale. Eucarpia Meet. on Triticale, Clermont Ferrand, pp. 35-47.

SYBENGA, J. 1983. Rye chromosome nomenclature and homoeology relationships. Workshop Report. Z. Pflanzenzuchtg, 90, 297-304.

THOMAS, J. B. AND KALTSIKES, P. J. 1974. A possible effect of heterochromatin on chromosome pairing. Proc. Nat. Acad. Sci., 71, 2787-2790.

YAMAMOTO, M. 1979. Cytological studies of heterochromatin function in Drosophila melanogaster male: autosomal meiotic pairing. Chromosoma, 72, 293-398. 